\title{
Inheritance of heat tolerance in perennial ryegrass (Lolium perenne, Poaceae): evidence from progeny array analysis
}

\author{
Wagdi S Soliman $^{\text {Corresp., } 1}$, Ahmed M Abbas ${ }^{2,3}$, Stephen J Novak ${ }^{4}$, Masahiro Fujimori ${ }^{5}$, Kazuhiro Tase ${ }^{6}$, Shu-ichi \\ Sugiyama \\ 1 Department of Horticulture, Faculty of Agriculture and Natural Resources, Aswan University, Aswan, Egypt \\ Department of Biology, College of Science, King Khalid University, Abha, Saudi Arabia \\ 3 Department of Botany and Microbiology, Faculty of Science, South Valley University, Qena, Egypt \\ 4 Department of Biological Sciences, Boise State University, Boise, Idaho, United States \\ ${ }^{5}$ Yamanashi Dairy Agricultural Station, Yamanashi, Japan \\ 6 National Agricultural Research Center for Hokkaido Region, Sapporo, Japan \\ 7 Hirosaki University, Hirosaki, Japan \\ Corresponding Author: Wagdi S Soliman \\ Email address: wagdi79@agr.aswu.edu.eg
}

Background: Heat stress is considered one of the most important environmental factors influencing plant physiology, growth, development, and reproductive output. The occurrence and damage caused by heat stress will likely increase with global climate change. Thus, there is an urgent need to better understand the genetic basis of heat tolerance, especially in cool season plants.

Materials and methods: In this study, we assessed the inheritance of heat tolerance in perennial ryegrass ( Lolium perenne L. subspecies perenne) , a cool season grass, through a comparison of two parental cultivars with their offspring. We crossed plants of a heat tolerant cultivar (Kangaroo Valley) with plants of a heat sensitive cultivar (Norlea), to generate $72 \mathrm{~F} 1$ hybrid progeny arrays. Both parents and their progeny were then exposed to heat stress for 40 days, and their photosynthetic performance (Fv/Fm values) and leaf $\mathrm{H}_{2} \mathrm{O}_{2}$ content were measured.

Results: As expected, Kangaroo Valley had significantly higher Fv/Fm values and significantly lower $\mathrm{H}_{2}$ $\mathrm{O}_{2}$ concentrations than Norlea. For the F1 progeny arrays, values of Fv/Fm decreased gradually with increasing exposure to heat stress, while the content of $\mathrm{H}_{2} \mathrm{O}_{2}$ increased. The progeny had a wide distribution of $\mathrm{Fv} / \mathrm{Fm}$ and $\mathrm{H}_{2} \mathrm{O}_{2}$ values at 40 days of heat stress. Approximately $95 \%$ of the $72 \mathrm{~F} 1$ progeny arrays had Fv/Fm values that were equal to or intermediate to the values of the two parental cultivars and $68 \%$ of the progeny arrays had $\mathrm{H}_{2} \mathrm{O}_{2}$ concentrations equal to or intermediate to their two parents.

Conclusion: Results of this study indicate considerable additive genetic variation for heat tolerance among the 72 progeny arrays generated from these crosses, and such diversity can be used to improve heat tolerance in perennial ryegrass cultivars. Our findings point to the benefits of combining physiological measurements within a genetic framework to assess the inheritance of heat tolerance, a complex plant response. 


\section{Inheritance of heat tolerance in perennial ryegrass}

2 (Lolium perenne, Poaceae): evidence from progeny

3 array analysis

4

5 Wagdi Saber Soliman ${ }^{1 *}$, Ahmed M. Abbas ${ }^{2,3}$, Stephen J. Novak ${ }^{4}$, Masahiro Fujimori ${ }^{5}$, Kazuhiro

6 Tase $^{6}$, Shu-ichi Sugiyama ${ }^{6}$

$7{ }^{1}$ Department of Horticulture, Faculty of Agriculture and Natural Resources, Aswan University,

8 Aswan, Egypt

$9 \quad{ }^{2}$ Department of Biology, College of Science, King Khalid University, Abha, Saudi Arabia

$10{ }^{3}$ Department of Botany and Microbiology, Faculty of Science, South Valley University, Qena,

11 Egypt

$12{ }^{4}$ Department of Biological Sciences, Boise State University, Boise, Idaho, USA

$13 \quad{ }^{5}$ Yamanashi Dairy Agricultural Station, Nagasaka, Yamanashi, Japan

$14{ }^{6}$ National Agricultural Research Center for Hokkaido Region, Sapporo, Japan

$15{ }^{7}$ Faculty of Agriculture and Life Science, Hirosaki University, Hirosaki, Japan 16

17 Corresponding Author:

18 Wagdi Saber Soliman ${ }^{1}$

19 Department of Horticulture, Faculty of Agriculture and Natural Resources, Aswan University, 20 Aswan 81528, Egypt

21 Email address: wagdi79@agr.aswu.edu.eg

Heat stress is considered one of the most important environmental factors influencing plant physiology, growth, development, and reproductive output. The occurrence and damage caused by heat stress will likely increase with global climate change. Thus, there is an urgent need to better understand the genetic basis of heat tolerance, especially in cool season plants. In this study, we assessed the inheritance of heat tolerance in perennial ryegrass (Lolium perenne L. subspecies perenne), a cool season grass, through a comparison of two parental cultivars with their offspring. We crossed plants of a heat tolerant cultivar (Kangaroo Valley) with plants of a heat sensitive cultivar (Norlea), to generate $72 \mathrm{~F} 1$ hybrid progeny arrays. Both parents and their 
33 progeny were then exposed to heat stress for 40 days, and their photosynthetic performance

34 (Fv/Fm values) and leaf $\mathrm{H}_{2} \mathrm{O}_{2}$ content were measured. As expected, Kangaroo Valley had

35 significantly higher Fv/Fm values and significantly lower $\mathrm{H}_{2} \mathrm{O}_{2}$ concentrations than Norlea. For

36 the F1 progeny arrays, values of Fv/Fm decreased gradually with increasing exposure to heat

37 stress, while the content of $\mathrm{H}_{2} \mathrm{O}_{2}$ increased. The progeny had a wide distribution of $\mathrm{Fv} / \mathrm{Fm}$ and

$38 \mathrm{H}_{2} \mathrm{O}_{2}$ values at 40 days of heat stress. Approximately $95 \%$ of the $72 \mathrm{~F} 1$ progeny arrays had

$39 \mathrm{Fv} / \mathrm{Fm}$ values that were equal to or intermediate to the values of the two parental cultivars and

$4068 \%$ of the progeny arrays had $\mathrm{H}_{2} \mathrm{O}_{2}$ concentrations equal to or intermediate to their two parents.

41 Results of this study indicate considerable additive genetic variation for heat tolerance among the

4272 progeny arrays generated from these crosses, and such diversity can be used to improve heat

43 tolerance in perennial ryegrass cultivars. Our findings point to the benefits of combining

44 physiological measurements within a genetic framework to assess the inheritance of heat

45 tolerance, a complex plant response.

\section{Introduction}

48 Based on the various habitats they occupy, plants require certain environmental conditions to 49 maintain the abundance and persistence of their populations (Harper, 1977). During their

50 lifetime, however, most plants experience abiotic stress when exposed to unfavorable chemical

51 and physical environmental conditions such as heavy metals, high salinity, excessive solar

52 radiation, freezing temperatures, severe drought, and extremely high temperatures (Nilsen and

53 Orcutt, 1996). Of these stressors, drought and heat stress are among the two most important

54 environmental factors influencing plant physiology, growth, development, and reproductive

55 output (i.e., yield) (Jiang and Huang, 2001; Prasad et al., 2008, Jespersen et al., 2017). 
According to Wahid et al. (2007), heat stress (or heat shock) in plants occurs when

57

58

59

60

61

62

63

64

65

66

67

68

69

70

71

72

73

74

75

76

77 of exposure to high temperatures, plant tissue type, and phenological stage, heat stress in plants 78

temperatures rise above a threshold level for sufficient time to result in irreversible damage to

plant growth and development. Although heat stress usually occurs with an increase in

temperature of $10-15^{\circ} \mathrm{C}$ above ambient; heat stress is also influenced by the intensity, duration,

and rate of increase in temperature (Wahid et al., 2012). Thus, heat stress in plants can occur on a

daily or seasonal basis and can vary from year-to-year. In addition, the occurrence and damage

caused by heat stress will likely increase with global climate change (Walter et al., 2013; Bita

and Gerats, 2013). Due to human activities, substantial increases in the concentration of

greenhouse gases are occurring, and global air temperatures are predicted to increase $1-4.5^{\circ} \mathrm{C}$

above the current level by 2100 , depending on different carbon emission scenarios (Rogelj et al.,

2012, IPCC, 2019). Moreover, human-caused climate change is also associated with extreme

climate events such as precipitation extremes, flooding, frosts, drought, and excessive heat (Niu

et al., 2014; Stott, 2016). Thus, future climate change is expected to cause serious damage to the

growth and yield of native plants and crop plants, especially $\mathrm{C}_{3}$ plants and crops (Lobell and

Field, 2007; Wahid et al., 2012).

Exposure of plants to excessively high temperatures can result in a range of complex

responses from molecular and cellular, to whole plant levels (Baniwal et al., 2004; Kotak et al., 2007; Wahid et al., 2012; Prasad et al., 2008, Mittler et al., 2011; Soliman et al., 2011). Once leaf temperatures rise above a threshold level $\left(35\right.$ to $40{ }^{\circ} \mathrm{C}$ for most plants), protein denaturation and loss of cell membrane fluidity begins to take place and cell damage and programmed cell death may occur (Huang and $\mathrm{Xu}, 2008$; Horvath et al. 2012). Depending on the intensity and duration can induce the following responses: 1) loss of cell water content, 2) reduced photosynthetic 
79 activity, 3) oxidative stress, 4) scorching of tissues and premature leaf senescence and abscission,

80 5) reduced growth rates through inhibition of shoot and root growth, 6) damage or alteration of

81 floral (reproductive) tissues, and 7) reduced seed number and quality (see Figure 1 in

82 Hasanuzzaman et al., 2013).

83 With heat stress, reductions in photosynthetic activity and efficiency may take place because

84 high temperatures can lead to the dissociation or inhibition of oxygen evolving complexes (OEC)

85 and reduce the activity of photosystem II (PSII) (Wahid et al., 2007). Photosynthetic

86 performance during heat stress can be quantified by measuring chlorophyll fluorescence

87 parameters (Baker and Oxborough 2004; Rosyara et al., 2010). One such parameter is Fv/Fm,

88 which is calculated as the ratio between variable fluorescence $(\mathrm{Fv}=\mathrm{Fm}-\mathrm{Fo})$ and maximum

89 fluorescence (Fm). Exposure to high temperatures can also induce oxidative stress in plants by

90 uncoupling enzymes and metabolic pathways which generates reactive oxygen species (ROS)

91 that can damage multiple cellular organelles and physiological processes (Locato et al. 2008;

92 Soliman et al., 2011; 2012; Hasanuzzaman et al., 2013). Reactive oxygen species (ROS) include

93 singlet oxygen, superoxide radical, hydroxyl radical, and hydrogen peroxide $\left(\mathrm{H}_{2} \mathrm{O}_{2}\right)$. Hydrogen

94 peroxide is the most stable ROS and its adverse effects in plants include membrane lipid

95 peroxidation, toxicity, and cell death. Interestingly, recent studies have highlighted the important

96 role of $\mathrm{H}_{2} \mathrm{O}_{2}$ as a signaling molecule in plants, triggering tolerance responses to abiotic stresses

97 (Suzuki et al., 2012; Baxter et al., 2014).

98 Plants are sessile organisms that are less likely to evade abiotic stressors. Thus, they have

99 developed several mechanisms for mitigating and surviving heat stress (see Figure 4 in

100 Hasanuzzaman et al., 2013). These mechanisms include short-term avoidance or acclimation

101 mechanisms and long-term phenological and morphological adaptive traits such as early 
102 maturation, enhanced root density and depth, changing leaf orientation and leaf rolling,

103 transpirational cooling, and/or alteration of membrane lipid compositions (Wahid et al., 2007;

104 2012; Prasad et al., 2008; Hasanuzzaman et al., 2013; Jespersen et al., 2017). Additionally, plants

105 have developed molecular, cellular, and physiological adaptations for tolerating heat stress

106 (Wahid et al., 2012; Hasanuzzaman et al., 2013). These include signaling cascades and

107 regulation of gene expression by transcription factors (Yang et al., 2014; Ohama et al., 2016;

108 Jespersen et al., 2017), expression of heat shock proteins (HSPs) and molecular chaperones

109 (Horvath et al., 2012; Davies et al., 2018), enzymatic and non-enzymatic antioxidant defense to

110 prevent the harmful effects of ROS (Gulen and Eris, 2004), and the production of osmo-

111 protectants or compatible solutes (Wahid et al., 2007; Hasanuzzaman et al., 2013). Clearly, heat

112 tolerance in plants is controlled by a complex set of many genes, interacting mechanisms, and

113 phenotypic traits, and not just a single gene, mechanism, or trait (Erdayani et al., 2020).

114 Perennial ryegrass (Lolium perenne $\mathrm{L}$. subspecies perenne) is a cool season $\left(\mathrm{C}_{3}\right)$, perennial

115 grass that has a caespitose (bunch) growth form and can grow to a height of approximately 10-90

$116 \mathrm{~cm}$. Perennial ryegrass originated in the Middle East, and then dispersed across Europe and

117 North Africa with the spread of agriculture (Balfourier et al. 2000). Perennial ryegrass has

118 subsequently been introduced around the globe and is considered a weed, or an invasive species,

119 in natural communities in many regions. It is also one of the most common pasture grasses in

120 temperate climatic regions where it is used as a forage grass for livestock and for hay production.

121 In addition, it is widely used as a turf grass (Bolaric et al., 2005a; 2005b; Wang et al., 2009), and

122 for restoration and conservation seedings. Perennial ryegrass is naturally a diploid species $(2 n=$

$1232 \mathrm{x}=14)$ (Bolaric et al., 2005b; Wang et al., 2009), but tetraploid $(2 \mathrm{n}=4 \mathrm{x}=28)$ cultivars have

124 also been developed (Nair, 2004). The grass has a two-locus self-incompatibility system, which 
125 leads to an obligately outcrossing mating system (Cornish et al. 1979). This mating system

126 ensures outbreeding among individuals and high amounts of genetic diversity within naturally

127 occurring populations (Bolaric et al., 2005a; 2005b; Wang et al., 2009). Many cultivars of

128 perennial ryegrass however are derived from a limited pool of foundational clones; and such

129 cultivars typically exhibit a limited amount of genetic variation (Guthridge et al., 2001).

130 Because perennial ryegrass is a cool season grass of temperate regions, it is generally

131 considered to be sensitive to heat stress (Li et al., 2020); although heat tolerant cultivars have

132 been developed (Wilkins, 1991). In addition, because the grass is widely cultivated and has high

133 economic value, experiments assessing heat stress in perennial ryegrass, especially comparisons

134 of heat tolerant and heat sensitive cultivars, have been conducted (e.g., Wehner and Watschke,

135 1981; Jiang and Huang, 2001; Zhou and Abaraha, 2007; Wang et al., 2017; Sun et al., 2020; Li et

136 al., 2020). For example, in a previous study we reported that a heat tolerant cultivar of perennial

137 ryegrass (Yatugadake-24) exhibited significantly higher photosynthetic performance (i.e., the

138 plants had higher Fv/Fm values) and lower leaf $\mathrm{H}_{2} \mathrm{O}_{2}$ content, compared to a heat sensitive

139 cultivar (Norlea) (Soliman et al., 2011). In another study, Soliman et al. (2012) exposed 25

140 diploid and tetraploid cultivars of perennial ryegrass to prolonged heat stress and found that

141 tetraploid cultivars had lower $\mathrm{H}_{2} \mathrm{O}_{2}$ content and experienced less oxidative stress than diploid

142 cultivars. Taken together, these studies indicate considerable genetic variation in heat tolerance

143 among perennial ryegrass cultivars and cytotypes. Yet, to the best of our knowledge, we are not

144 aware of any assessment of the genetic basis of heat tolerance in perennial ryegrass.

145 In this study, we assessed the inheritance of heat tolerance in perennial ryegrass through a

146 direct comparison of parental cultivars with their offspring, through progeny array analysis. This

147 was accomplished by crossing plants of a heat tolerant cultivar of perennial ryegrass with plants 
148 of a heat sensitive cultivar, to generate multiple F1 progeny arrays. Both parents and their

149 progeny were then exposed to long-term heat stress, and their photosynthetic performance and

150 leaf $\mathrm{H}_{2} \mathrm{O}_{2}$ concentrations were measured. In addition, several leaf growth parameters were

151 measured before the imposition of heat stress. The specific goals of this research were to, 1)

152 quantify the level of heat tolerance in the two parental cultivars, 2) determine variation in heat

153 tolerance among the F1 progeny, and 3) compare the level of heat tolerance of the parents with

154 their F1 progeny to assess the inheritance of this complex and important plant response. Results

155 of this study will improve our understanding of the genetic basis of heat tolerance in perennial

156 ryegrass, assist in estimating the heritability of this trait, and aid in the identification and

157 selection of plants with even higher levels of heat tolerance for use in plant breeding programs.

158

159 MATERIALS AN METHODS

160 Plant material

161 Plants of two diploid perennial ryegrass cultivars were used as the parents in this study.

162 Kangaroo Valley (strain K7) is a heat tolerant cultivar developed in New South Wales, Australia,

163 that is well-suited to dry, hot regions (Wilkins, 1991; Blumenthal et al., 1996) and Norlea (strain

164 N4) is a heat sensitive cultivar developed in Canada (Soliman et al., 2011; 2012). Based on the

165 breeding programs that developed them, both strains of the two cultivars exhibit limited genetic

166 diversity (Blumenthal et al., 1996; Soliman et al., 2011).

167 Flowers of each of these two cultivars were crossed through hand-pollination, after they were

168 emasculated. These crosses were performed using 72 different pairs of the two cultivars. An

169 individual of the Kangaroo Valley cultivar was always used as the pollen donor and an

170 individual of the Norlea cultivar was always used as the maternal parent. Sufficient hand- 
171 pollinations were conducted to generate at least six seeds from each pair of the two cultivars;

172 thus, 72 full-sib, F1 hybrid progeny arrays, each consisting of six seeds, were generated and

173 employed in our experiment design. Crosses were conducted at the Yamanashi Dairy

174 Experimental Station, Yamanashi, Japan.

175 Heat stress treatment

176 Our heat stress experiment was conducted using the procedures described by Soliman et al.

177 (2012). The seeds/seedlings of the two perennial ryegrass strains (K7 and N4) used in the heat

178 stress experiments were not the same individuals used to generate the progeny arrays; but

179 because these two strains have limited genetic diversity, seeds of these two cultivars are

180 genetically uniform. Six seeds (replicates) of each of the two parental cultivars and six seeds

181 from each of the $72 \mathrm{~F} 1$ progeny arrays were germinated on wet filter paper in petri dishes. The

182 grass does not require any other treatments to achieve high rates of germination. Seedlings were

183 transplanted into pots (two seeds per pot), $7.5 \mathrm{~cm}$ in diameter and $8 \mathrm{~cm}$ deep, with a sandy loam

184 potting soil containing $0.35 \mathrm{~g}$ of $\mathrm{N}, \mathrm{P} 2 \mathrm{O} 5$, and $\mathrm{K} 2 \mathrm{O}$ for every kilogram of soil (N-P-K ratio of

185 2:1:2). The seedlings were grown in a controlled growth chamber with day/night temperatures of

$18623 / 16^{\circ} \mathrm{C}$, a $16 \mathrm{~h} / 8 \mathrm{~h}$ day/night photoperiod (from 4:00-20:00 h), with photon flux density of 250

$187 \mu \mathrm{mol} \mathrm{m} \mathrm{m}^{-2} \mathrm{~s}^{-1}$, and a constant relative humidity of $70 \%$. Forty days after transplanting, all the

188 plants were exposed to $30{ }^{\circ} \mathrm{C}$ for 3 days for acclimation to a higher temperature, after which the

189 plants were exposed to heat treatments $\left(36 / 30^{\circ} \mathrm{C}\right.$, day/night temperatures) for 40 day. Plants

190 were watered daily to avoid water (drought) stress. The heat stress experiment was set up in a

191 randomized complete block design, with six replicates for each of the two parental cultivars and 192 each of the 72 F1 progeny arrays.

193 Leaf growth traits 
194 Leaf growth traits were measured prior to the imposition of heat stress. For each seedling, the 195 second fully matured leaf was selected for measurements. Specific leaf area (SLA) and its 196 components were determined according to the method of Witkowski and Lamont (1991).

197 Specific leaf area is calculated as the ratio of leaf area (LA) to leaf dry mass (LDM). Other leaf 198 measurements included leaf water content (LWC), leaf thickness (LT), and leaf density (LD).

199 Before the start of the heat stress treatment, the second mature leaf from each plant was 200 harvested, its fresh weight was recorded, and it was immediately soaked in a $50 \mathrm{ml}$ flask filled 201 with water to perform measurements with leaves at full turgor. An image of each leaf was then 202 digitally recorded using an optical scanner (D660U, Canon, Tokyo, Japan). The leaf area was 203 calculated using Image J software (version 1.6, National Institutes of Health). The leaves were 204 then oven dried at $80{ }^{\circ} \mathrm{C}$ for two days, and their dry weights were recorded. Leaf thickness was 205 determined using microscopic observation of leaf transverse sections using MICROM 206 (HM400R, Walldorf, Germany) as previously described (Soliman et al., 2012). Leaf density $207\left(\mathrm{mg} / \mathrm{cm}^{-3}\right)$, or dry matter concentration, was calculated by dividing leaf dry mass by leaf volume. 208 Leaf volume was determined as the product of leaf area and mean leaf thickness.

\section{Photosynthetic performance}

210 Chlorophyll fluorescence (Fv/Fm) values were measured before the initiation of heat acclimation 211 and at 10-day intervals thereafter. Individual seedlings were maintained in the dark for 20 min 212 for dark adaptation and then the minimum $\left(\mathrm{F}_{0}\right)$ and maximal $(\mathrm{Fm})$ levels of fluorescence were 213 measured three times for each individual using a portable photosynthesis measuring system (LI214 6400, Li-Cor, Lincoln, Nebraska, USA). Fv/Fm provides an estimate of the maximum quantum 215 yield of PSII (Butler, 1978; Zhou et al., 2015); where heat tolerant plants typically exhibit higher 216 Fv/Fm values (i.e., they have higher photosynthetic performance) than heat sensitive plants. 


\section{Oxidative stress}

218 Heat sensitive plants experience greater oxidative stress than heat tolerant plants because plants

219 that are heat sensitive (i.e., experiencing heat stress) produce higher concentrations of $\mathrm{H}_{2} \mathrm{O}_{2}$ than 220 those that are heat tolerant. Hydrogen peroxide $\left(\mathrm{H}_{2} \mathrm{O}_{2}\right)$ concentration values were determined 221 according to the methods described by Soliman et al. (2011). There were two $\mathrm{H}_{2} \mathrm{O}_{2}$ measurement 222 periods; before the imposition of heat stress and at 40 days of exposure to heat stress. Hydrogen 223 peroxide $\left(\mathrm{H}_{2} \mathrm{O}_{2}\right)$ content of leaves was measured using a modified version of the ferrous 224 ammonium sulphate/xylenol orange (eFOX) method described by Cheeseman (2006) and Queval 225 et al. (2008). Leaf extracts were obtained by grinding $50 \mathrm{mg}$ of leaf tissue, first in liquid nitrogen 226 and then in $500 \mu \mathrm{L}$ of $0.1 \mathrm{M}$ potassium phosphate buffer $\left(\mathrm{pH}\right.$ 6.5) containing $5 \mathrm{mM} \mathrm{NaN}_{3}$. 227 Extracts were centrifuged at $10,000 \mathrm{rpm}(8385 \mathrm{~g})$ at $5^{\circ} \mathrm{C}$ for $5 \mathrm{~min}$. For every $200 \mu \mathrm{L}$ of the 228 extract, $5 \mathrm{~mL}$ of the solution containing $250 \mu \mathrm{M}$ ferrous ammonium sulphate, $100 \mu \mathrm{M}$ sorbitol, $229100 \mu \mathrm{M}$ xylenol orange, $1 \%$ ethanol, and $25 \mathrm{mM} \mathrm{H}_{2} \mathrm{SO}_{4}$ were added. The assay consisted of 230 measuring the difference in absorbance between $550 \mathrm{~nm}$ and $800 \mathrm{~nm}$, after $15 \mathrm{~min}$, with a 231 spectrophotometer.

\section{Statistical analyses}

233 Analysis of variance (ANOVA) was used to test for significant differences between the two 234 parental cultivars (six replicates per cultivar) and among the progeny for leaf growth traits; and 235 among the progeny for $\mathrm{Fv} / \mathrm{Fm}$ values and $\mathrm{H}_{2} \mathrm{O}_{2}$ content (six replicates for each of the $72 \mathrm{~F} 1$ 236 hybrid progeny arrays), at different days of exposure to heat stress. Because the same plants 237 were used to measure Fv/Fm values over time, and these data were not independent of each 238 other, we used one-way repeated measures multivariate analysis of variance (MANOVA) to test 239 whether the two cultivars were significantly different. We used a t-test to test for significant 
240 differences in the $\mathrm{H}_{2} \mathrm{O}_{2}$ content between two cultivars before and at 40 days of heat stress. A

241 random-effects regression model was used to assess the relationship between leaf growth traits

242 and $\mathrm{Fv} / \mathrm{Fm}$ values and $\mathrm{H}_{2} \mathrm{O}_{2}$ content for the $72 \mathrm{~F} 1$ progeny arrays at 40 days after the imposition

243 of heat stress, with leaf traits as fixed effects and $\mathrm{Fv} / \mathrm{Fm}$ values and $\mathrm{H}_{2} \mathrm{O}_{2}$ content as random

244 variables. Another random-effects regression model was used to assess the relationship between

$245 \mathrm{Fv} / \mathrm{Fm}$ values and $\mathrm{H}_{2} \mathrm{O}_{2}$ content for the $72 \mathrm{~F} 1$ progeny arrays at 40 days after the imposition of

246 heat stress, with $\mathrm{Fv} / \mathrm{Fm}$ values and $\mathrm{H}_{2} \mathrm{O}_{2}$ content as random variables. All statistical analyses

247 were carried out using JMP (ver 4. SAS Institute, Cary, NC, USA).

248

249 Results

250 Prior to heat stress treatment

251 Before the imposition of heat stress, there were no statistically significant differences in

252 chlorophyll fluorescence $(\mathrm{Fv} / \mathrm{Fm})$ values and hydrogen peroxide $\left(\mathrm{H}_{2} \mathrm{O}_{2}\right)$ content for the two

253 parental cultivars (Figs. 1 and 2).

254 Prior to experiencing heat stress, the two parental cultivars did not exhibit significant

255 differences for three of five leaf growth traits and there were significant differences in two traits,

256 leaf water content and leaf thickness (Fig. 3 and Table 1). The two exceptions to this pattern

257 were leaf water content and leaf thickness. Conversely, significant phenotypic variation was

258 observed for all leaf growth traits among the 72 progeny arrays (Table 1), and they exhibited a

259 normal distribution for all five leaf growth traits (Fig. 3). For instance, 71 of 72 (98.6\%) progeny

260 arrays had leaf area values that were equal to or greater than the values of their two parents

261 (Figure 3a). However, for leaf water content, 60 of $72(83 \%)$ progeny arrays had values that were

262 equal to or intermediate to the values of the two parental cultivars (Fig. 3c). There was no

Peer) reviewing PDF | (2020:09:52700:5:0:NEW 5 Jun 2021) 
263 relationship (no significant correlations) between the leaf growth traits and $\mathrm{Fv} / \mathrm{Fm}$ values and

$264 \mathrm{H}_{2} \mathrm{O}_{2}$ content at 40 days after the imposition of heat stress (data not shown).

\section{Response to heat stress: parental cultivars}

266 The two parental cultivars did not exhibit statistically significant differences in $\mathrm{Fv} / \mathrm{Fm}$ values for

267 the first three measurement periods, at $0 \mathrm{~d}$ and after the imposition of heat stress $(10 \mathrm{~d}$ and $20 \mathrm{~d})$.

268 However, the two parents did show significant differences in their $\mathrm{Fv} / \mathrm{Fm}$ values at $30 \mathrm{~d}$ and $40 \mathrm{~d}$ 269 of heat stress, with the Kangaroo Valley cultivar having significantly higher values (i.e., higher 270 photosynthetic performance) (Figs. 1 and 4a). At $40 \mathrm{~d}$ of heat stress, both parental cultivars had

271 higher $\mathrm{H}_{2} \mathrm{O}_{2}$ values compared to before the imposition of stress. At $40 \mathrm{~d}$ of exposure to heat

272 stress, Norlea, the heat-sensitive cultivar, had significantly higher $\mathrm{H}_{2} \mathrm{O}_{2}$ content than the

273 Kangaroo Valley cultivar (Figs. 2 and 4b). This result indicates that the Norlea cultivar

274 experienced more oxidative stress under these conditions.

\section{Response to heat stress: progeny arrays}

$276 \mathrm{Fv} / \mathrm{Fm}$ values for the 72 progeny arrays were significantly different for all time periods measured 277 ( $0 \mathrm{~d}$ to $40 \mathrm{~d}$ ) (Table 2$)$. Fv/Fm values of the progeny arrays decreased gradually with increased 278 duration of heat stress (Table 2), and a broad distribution of $\mathrm{Fv} / \mathrm{Fm}$ values was observed at $40 \mathrm{~d}$ 279 (Fig. 4a). Sixty-nine of 72 (approximately 95\%) of the progeny arrays had Fv/Fm values that 280 were equal to or intermediate to the values of the two parental cultivars.

281 The progeny had statistically significant variation in $\mathrm{H}_{2} \mathrm{O}_{2}$ values both prior to the imposition 282 of heat stress (at $0 \mathrm{~d}$ ) and at 40 days after the imposition of heat stress (at $40 \mathrm{~d}$ ). Additionally, 283 the progeny arrays undergoing heat stress experienced an increase in their $\mathrm{H}_{2} \mathrm{O}_{2}$ content (Table 2, 284 Fig. 4b). At 40 days after the imposition of heat stress, 49 of 72 (68\%) of the progeny arrays had $285 \mathrm{H}_{2} \mathrm{O}_{2}$ values that were equal to or intermediate to the two parental cultivars. 
At 40 days of exposure to heat stress, the two cultivars and the 72 progeny arrays exhibited a

287

288

289

290

\section{Discussion}

292 Perennial ryegrass is one of the most common pasture and turf grasses in temperate climate 293 regions around the globe (Bolaric et al., 2005a; 2005b; Wang et al., 2009). Because it is a cool294 295 296

297 298 season grass, it is thought to be sensitive to heat stress (Li et al., 2020); however, plant breeders have also developed heat tolerant cultivars (Wilkins, 1991). In addition, because many strains of these cultivars are derived from a limited number of individuals, and possess limited genetic diversity (Guthridge et al., 2001), they can function similarly to inbred lines. Thus, features of the two perennial ryegrass cultivars we used were essential in designing our study. First, the Kangaroo Valley cultivar is heat tolerant and Norlea is heat sensitive; therefore, these two cultivars are genetically and phenotypically distinct. Second, different seeds of each of the two strains are genetically (and phenotypically) uniform, thus we could reliably use different seeds of each cultivar to generate the 72 progeny arrays and in the heat stress experiment.

The results of the current study are generally consistent with others that have assessed photosynthetic performance and oxidative stress with heat stress in heat tolerant and heat sensitive cultivars of perennial ryegrass (Wehner and Watschke, 1981; Jiang and Huang, 2001; Zhou and Abaraha, 2007; Soliman et al., 2011; 2012; Li et al., 2020). These results show that heat tolerant cultivars of perennial ryegrass had significantly higher photosynthetic performance (higher Fv/Fm values) and lower leaf $\mathrm{H}_{2} \mathrm{O}_{2}$ content, compared to heat sensitive cultivars. At 40

Peer) reviewing PDF | (2020:09:52700:5:0:NEW 5 Jun 2021) 
309 days of heat stress, approximately $95 \%$ of the progeny arrays had $\mathrm{Fv} / \mathrm{Fm}$ values that were equal

310 to or intermediate to the values of the two parental cultivars and $68 \%$ of the progeny arrays had

$311 \mathrm{H}_{2} \mathrm{O}_{2}$ concentrations equal to or intermediate to the two parental cultivars. Conversely, other

312 members of this progeny array have phenotypic trait values beyond their the two parents.

313 The phenotypic trait distribution for the five leaf growth traits, $\mathrm{Fv} / \mathrm{Fm}$ values, and $\mathrm{H}_{2} \mathrm{O}_{2}$

314 content for the 72 progeny arrays is consistent with the distribution expected for traits that are

315 determined by multiple loci (i.e., they are quantitative genetic traits) (Falconer and Mackay,

316 1996). The distribution for these phenotypic traits indicates considerable additive genetic

317 variation among the F1 hybrid progeny arrays, which resulted from crossing the Kangaroo

318 Valley and Norlea cultivars. This additive genetic variation was generated by genetic

319 recombination during gamete formation by the parental plants. In addition, the clustering of

320 many progeny data points near the Kangaroo Valley cultivar, which served as the paternal parent

321 in the cross, may signal the role of dominance (the Kangaroo Valley cultivar possesses dominant

322 alleles) or epistatic interactions in the phenotypic expression of photosynthetic performance and

323 leaf $\mathrm{H}_{2} \mathrm{O}_{2}$ content among the progeny arrays (Falconer and Mackay, 1996). Determining the

324 relative contributions of additive genetic variation, and other genetic processes, in the phenotypic

325 expression of the quantitative traits we examined should be the focus of future research.

326 The photochemical efficiency of PSII, measured by chlorophyll fluorescence (Fv/Fm), is the

327 most sensitive component associated with photosynthesis and it is used commonly to evaluate

328 heat tolerance in plants (Maxwell and Johnson, 2000). Under elevated temperatures, ROS are

329 produced through specific metabolic pathways such as photosynthesis and photorespiration

330 (Queval et al., 2008). The generation of ROS results from a disrupted balance between

331 photochemical and biochemical reactions inhibiting photosynthesis processes (Wahid et al., 
332 2007). Plants however have developed several mechanisms for tolerance to stress such as

333 antioxidant enzymes and HSPs.

334 The distribution of $\mathrm{Fv} / \mathrm{Fm}$ and $\mathrm{H}_{2} \mathrm{O}_{2}$ values among the 72 progeny arrays suggests genetic

335 variation for the genes responsible for heat tolerance. These genes control antioxidant activity

336 and the formation of HSPs, which in turn inhibit the formation of ROS and maintain membrane

337 stability and thus increase photosynthetic efficiency, improve plant growth, and allow plants to

338 endure heat stress. These results suggest that the phenotypic variation in heat tolerance exhibited

339 by the 72 progeny arrays analyzed in this study is closely associated with the ability to suppress

340 oxidative stress. This is consistent with previous findings among cultivars of perennial ryegrass

341 (Soliman et al., 2011, 2012).

342 Leaf growth traits also play important roles in plant acclimation to environmental stress

343 (Terashima et al., 2011). We did not however detect a relationship between the leaf growth traits

344 we measured prior to the imposition of heat stress and $\mathrm{Fv} / \mathrm{Fm}$ values and $\mathrm{H}_{2} \mathrm{O}_{2}$ content at 40 days

345 after the imposition of heat stress. Results of the current study differ from those of our previous

346 findings with other perennial ryegrass cultivars (Soliman et al., 2011, 2012), which showed

347 significant relationships between leaf traits, especially leaf thickness, and ROS generation and

348 heat tolerance. This discrepancy likely results from genetic difference of the parental cultivars

349 used in the previous studies. Clearly, heat tolerance is a complex plant response governed by 350 many factors, not least of which is the genetic background of the plants (cultivars) being studied.

352 Conclusions

353 To the best of our knowledge, this study represents the first assessment of the genetic basis of

354 heat tolerance in perennial ryegrass. This study combined physiological measurements ( $\mathrm{Fv} / \mathrm{Fm}$ 
355

356

357

358

359

360

361

362

363

364

365

366

367

368

369

370

371

372

373

374

375

376

377

and $\mathrm{H}_{2} \mathrm{O}_{2}$ content) within a genetic framework (i.e., parent-offspring comparison) to assess the inheritance of heat tolerance in this grass. Based on the specific crosses used in this study (the

Kangaroo Valley and Norlea cultivars), our results indicate considerable additive genetic

variation within these progeny arrays. This diversity can be used to improve heat tolerance in cultivars of perennial ryegrass using conventional plant breeding, and could also facilitate marker-assisted breeding, and/or pave the way for characterizing the underlying genetic and genomic factors which could be useful for developing plants with improved heat tolerance (Sreenivasulu et al., 2007; Barnabás et al. 2008; Tricker et al., 2018).

\section{Acknowledgements}

The authors extend their appreciation to the Deanship of Scientific Research at King Khalid University for funding this work through Research Group Project (Number R.G.P.1/210/41).

\section{References}

Baker NR, Oxborough K. 2004. Chlorophyll fluorescence as a probe of photosynthetic productivity. Springer, Dordrecht, The Netherlands, pp. 66-79.

Balfourier F, Imbert C, Charmet G. 2000. Evidence for phylogenetic structure in Lolium species related to the spread of agriculture in Europe. A cpDNA study. Theoretical and Applied Genetics 101: 131-138.

Baniwal SK, Bharti K, Chan KY, Fauth M, Gangion factorsnuli A, Kotak S, Mishra SM, Nover L, Port M, Scharf K-D, Tripp J, Weber C, Zielinski D, von Koskull-Doring P. 2004. Heat stress response in plants: a complex game with chaperones and more than twenty heat-stress transcription factors. Journal of Bioscience 29: 471-487. 
378 Barnabás B, Jäger K, Fehér A. 2008. The effect of drought and heat stress on reproductive

379

380

381

382

383

384

385

386

387

388

389

390

391

392

393

394

395

396

397

398 processes in cereals. Plant, Cell and Environment 31: 11-38.

Baxter A, Mittler R, Suzuki N. 2014. ROS as key players in plant stress signaling. Journal of Experimental Botany 65: 1229-1240.

Bita CE, Gerats T. 2013. Plant tolerance to high temperature in a changing environment: scientific fundamental and production of heat stress-tolerant crops Frontiers in Plant Science 4: Article 273.

Blumenthal MJ, Prakash K, Leonforte A, Cunningham PJ, Nicol HI. 1996. Characterisation of the Kangaroo Valley ecotype of perennial ryegrass (Lolium pernne). Australian Journal of Agricultural Research 47: 1131-1142.

Bolaric S, Barth S, Melchinger AE, Posselt UK. 2005a. Genetic diversity in European perennial ryegrass cultivars investigated with RAPD markers. Plant Breeding 124: 161-166

Bolaric S, Barth S, Melchinger AE, Posselt UK. 2005b. Molecular genetic diversity within and among German ecotypes in comparison to European perennial ryegrass cultivars. Plant Breeding 124: 257-262.

Butler JW. 1978. Energy distribution in the phytochemical apparatus of photosynthesis. Annual Review of Plant Physiology 29: 345-378.

Cheeseman JM. 2006. Hydrogen peroxide concentrations in leaves under natural conditions. Journal of Experimental Botany 57: 2435-2444.

Cornish MA, Hayward MD, Lawrence MJ. 1979. Self-incompatibility in ryegrass. I. Genetic control in diploid Lolium perenne L. Heredity 43: 95-106. 
399 Davies M, Ecroyd H, Robinson SA, French K. 2018. Stress in native grasses under

400 ecologically relevant heat waves. PLOS ONE 13(10): e0204906.

$401 \quad$ https://doi.org/10.1371/journal.pone.0204906

402 Erdayani E, Nagarajan R, Grant NP, Gill KS. 2020. Genome-wide analysis of the

403

404

405

406

407

408

409

410

411

412

413

414

415

416

417

418

419

420 HSP101/CLPB gene family for heat tolerance in hexaploid wheat. Scientific Reports 10: 3948. https://doi.org/10.1038/s41598-020-60673-4

Falconer DS, Mackay TFC. 1996. Introduction to Quantitative Genetics. $4^{\text {th }}$ Edition, Prentice Hall, Essex, UK.

Gulen H, Eris A. 2004. Effects of heat strss on peroxidase activity and total protein content in strawberry plants. Plant Science 166: 739-744.

Guthridge KM, Dupal MP, Kolliker R, Jones ES, Smith KF, Forster JW. 2001. AFLP analysis of genetic diversity within and between populations of perennial ryegrass (Lolium perenne L.). Euphytica 122: 191-201.

Harper JL. 1977. Population Biology of Plants. Academic Press: New York, 892 pp.

Hasanuzzaman M, Nahar K, Alam MM, Roychowdhury R, Fujita M. 2013. Physiological, biochemical, and molecular mechanisms of heat stress tolerance in plants. International Journal of Molecular Sciences 14: 9643-9684.

Horvath I, Glatz A, Nakamoto H, Mishkind ML, Munnik T, Saidi Y, Goloubinoff P, Harwood JL, Vigh L. 2012. Heat shock response in photosynthetic organisms: membrane and lipid connections. Progress in Lipid Research 51: 208-220.

Huang B, Xu C. 2008. Identification and characterization of proteins associated with plant tolerance to heat stress. Journal of Integrative Plant Biology 50: 1230-1237. 
421 IPCC. 2019. Climate Change and Land: an IPCC special report on climate change,

422 desertification, land degradation, sustainable land management, food security, and

423 greenhouse gas fluxes in terrestrial ecosystems. Website www.ipcc.ch

424 Jespersen D, Belanger FC, Huang B. 2017. Candidate genes and molecular markers associated

425 with heat tolerance in colonial bentgrass. PLOS ONE 12(2): eo171183.

$426 \quad$ https://doi.org/10.1371/journal.pone.0171183

427 Jiang Y, Huang B. 2001. Physiological responses to heat stress alone or in combination with

428 drought: a comparison between tall fescue and perennial ryegrass. HortScience 36: 682-686.

429 Kotak S, Larkindale J, Lee U, von Koskull-Doring P, Vierling E, Scharf K-D. 2007.

430 Complexity of heat stress response in plants. Current Opinions in Plant Science 10: 310-

431316.

432 Li M, Jannasch AH, Jiang Y. 2020. Growth and hormone alterations in response to heat stress

433 in perennial ryegrass accessions differing in heat tolerance. Journal of Plant Growth

$434 \quad$ Regulation 39: 1022-1029.

435 Lobell DB, Field CB. 2007. Global scale climate-crop yield relationships and the impacts of 436 recent warming. Environmental Research Letters 2: 014002 (7 pp).

437 Locato V, Gadaleta C, De Gara L, De Pinto MC. 2008. Production of reactive species and 438 modulation of antioxidant network in response to heat shock: a critical balance of cell fate. $439 \quad$ Plant, Cell \& Environment 31: 1606-1619.

440 Maxwell K, Johnson GN. 2000. Chlorophyll fluorescence- a practical guide. Journal of $441 \quad$ Experimental Botany 51: 659-668.

442 Mittler R, Finka A, Goloubinoff P. 2011. How do plants feel the heat? Trends in Biochemical $443 \quad$ Sciences 37: 118-125. 
444 Nair RM. 2004. Developing tetraploid perennial ryegrass (Lolium perenne L.) populations. New 445 Zealand Journal of Agricultural Research 47: 45-49.

446 Nilsen ET, Orcutt DM. 1996. The Physiology of Plants under Stress: Abiotic Factors. London: 447 John Wiley \& Sons, 689 pp.

448 Niu S, Luo Y, Li D. Cao S, Xia J, Li J, Smith MD. 2014. Plant growth and mortality under 449 climatic extremes: an overview. Environmental and Experimental Botany 98: 13-19.

450 Ohama N, Sato H, Shinozaki K, Yamaguchi-Shinozaki Kaohiko. 2016. Transcriptional 451 regulatory network of plant heat stress response. Trends in Plant Science 22: 53-65.

452 Prasad PVV, Staggenborg SA, Ristic Z. 2008. Impacts of drought and/or heat stress on 453 physiological, developmental, growth, and yield processes of crop plants. In: Ahuja LR, 454 Reddy VR, Saseendran SA, Yu Q, eds. Response of crops to limited water: understanding 455 and modeling water stress effects on plant growth processes, Vol. 1. London: John Wiley \& $456 \quad$ Sons $301-355$.

457 Queval G, Hager J, Gakière B, Noctor G. 2008. Why are literature data for $\mathrm{H}_{2} \mathrm{O}_{2}$ contents so 458 variable? A discussion of potential difficulties in the quantitative assay of leaf extracts. Journal of Experiment Botany 59: 135-146.

Rogelj J, Meinhausen M, Knutti R. 2012. Global warming under old and new scenarios using IPCC climate sensitivity range estimates. Nature Climate Change 2: 248-253.

Rosyara UR, Subdedi S, Sharma RC, Duveiller E. 2010. Photochemical efficiency and SPAD value as indirect selection criteria for combined selection of spot blotch and terminal heat stress in wheat. Journal of Phytopathology 158: 813-821. 
465 Soliman WS, Fujimori M, Tase K, Sugiyama S. 2011. Oxidative stress and physiological 466 damage under prolonged heat stress in C3 grass Lolium perenne. Grassland Science 57: 467 101-106. https://doi.org/10.1111/j.1744-697X.2011.00214.X

468 Soliman WS, Fujimori M, Tase K, Sugiyama S. 2012. Heat tolerance and suppression of 469 oxidative stress: comparative analysis of 25 cultivars of the $\mathrm{C} 3$ grass Lolium perenne. $470 \quad$ Environmental and Experimental Botany 78: 10-17.

$471 \quad$ https://doi.org/10.1016/j.envexpbot.2011.12.013

472 Sreenivasulu N, Sopory SK, Kishor PB. 2007. Deciphering the regulatory mechanisms of 473 abiotic stress tolerance in plants by genomic approaches. Gene 388: 1-13.

474 Stott P. 2016. How climate change affects extreme weather events. Science 352: 1517-1518.

475 Sun T, Shao K, Huang Y, Lei Y, Tan L, Chan Z. 2020. Natural variation analysis of perennial 476 ryegrass in response to abiotic stress highlights LpHSFC1b as a positive regulator of heat $477 \quad$ stress. Environmental and Experimental Botany 179: 104192.

$478 \quad \underline{\text { https://doi.org/10.1016/j.envexpbot.2020.104192 }}$

479 Suzuki N, Koussevitzky S, Mittler R, Miller G. 2012. ROS and redox signalling in the $480 \quad$ response of plants to abiotic stress. Plant, Cell \& Environment 35: 259-270.

481 Terashima I, Hanba YT, Tholen D, Niinemets Ü. 2011. Leaf functional anatomy in relation to 482 photosynthesis. Plant Physiology 155: 108-116.

483 Tricker PJ, ElHabti A, Schmidt J, Fleury D. 2018. The physiological and genetic basis of 484 combined drought and heat tolerance in wheat. Journal of Experimental Botany 69: 3195485 3210. https://doi.org/10.1093/jxb/ery081 
486 Wahid A, Farooq M, Hussain I, Rasheed R, Galani S. 2012. Response and management of 487 heat stress. In: Ahmad P, Prasad MNV, eds. Environmental adaptations and stress tolerance of plants in the era of climate change. Berlin: Springer Science+Business Media135-157.

489

490

491

492

493

494

495

496

497

498

499

500

501

502

503

504

505

506

507

Wahid A, Gelani S, Ashraf M, Foolad MR. 2007. Heat tolerance in plants: an overview. Environmental and Experimental Botany 61: 199-223.

Walter J, Jentsch, Beierkuhnlein C, Kreyling J. 2013. Ecological stress memory and cross stress tolerance in the face of climate extremes. Environmental and Experimental Botany 94: 3-8. https://doi.org/10.1016/j.envexpbot.2012.02.009

Wang J, Dobrowolski MP, Cogan NOI, Forster JW, Smith KF. 2009. Assignment of individual genotypes to specific forage cultivars of perennial ryegrass based on SSR markers. Crop Science 49: 49-58.

Wang K, Liu Y, Tian J, Huang K, Shi T, Dai X, Zhang W. 2017. Transcriptional profiling and identification of heat-responsive genes in perennial ryegrass by RNA-sequencing. Frontiers in Plant Sciences 8: 1032.

Wehner DJ, Watschke TL. 1981. Heat tolerance in Kentucky bluegrasses, perennial ryegrasses, and annual bluegrass. Agronomy Journal 73: 79-84.

Wilkins PW. 1991. Breeding perennial ryegrass for agriculture. Euphytica 52: 201-214.

Witkowski ETF, Lamont BB. 1991. Leaf specific mass confounds leaf density and thickness. Oecologia 88: 486-493.

Yang Z, Wang Y, Gao Y, Zhou Y, Zhng E, Hu Y, Yuan Y, Liang G. 2014. Adaptive evolution and divergent expression of heat stress transcription factors in grasses. $B M C$ Evolutionary Biology 14: 147 https://www.biomedcentral.com/1471-2148/14/147. 
508 Zhou R, Yu X, Kjaer KH, Rosenqvist E, Ottosen C-O. 2015. Screening and validation of 509 tomato genotypes under heat stress using Fv/Fm to reveal the physiological mechanism of $510 \quad$ heat tolerance. Environmental and Experimental Botany 118: 1-11.

511 Zhou S, Abaraha A. 2007. Response to heat stress in warm season and cool season turf grass $512 \quad$ cultivars. Scientific Research and Essay 2: 95-100.

513 


\section{Table $\mathbf{1}$ (on next page)}

Table 1. Analysis of Variance for chlorophyll fluorescence (Fv/Fm) and hydrogen peroxide content $\left(\mathrm{H}_{2} \mathrm{O}_{2}, \mu \mathrm{mol} \mathrm{mgFW}^{-1}\right)$ among 72 genotypes at different durations of continuous exposure to heat stress. 
Table 1. Analysis of Variance (ANOVA) for leaf growth traits for the two parental cultivars and the $72 \mathrm{~F} 1$ progeny arrays prior to the imposition of heat stress.

Leaf growth traits

Leaf area $\left(\mathrm{cm}^{2}\right)$

Specific leaf area $\left(\mathrm{mm}^{2} \mathrm{mg}^{-1}\right)$

Leaf water content (\%)

Leaf thickness $(\mu \mathrm{m})$

Leaf density $\left(\mathrm{mg} \mathrm{cm}^{-3}\right)$

\section{Parental cultivars}

\begin{tabular}{ccc} 
Norlea & Kangaroo & F value \\
\hline 1.72 & 1.81 & $0.07^{\mathrm{ns}}$ \\
26.96 & 24.43 & $1.01^{\mathrm{ns}}$ \\
81.3 & 77.5 & $8.96^{*}$ \\
169 & 198 & $7.75^{*}$ \\
221 & 211 & $0.27^{\mathrm{ns}}$
\end{tabular}

72 F1 progeny

\begin{tabular}{cc} 
Range & F value \\
\hline $0.87 \sim 7.44$ & $7.48^{* * *}$
\end{tabular}

$19.0 \sim 35.4 \quad 3.38^{* * *}$

$74.5 \sim 85.2 \quad 4.76^{* * *}$

$141 \sim 242 \quad 5.68^{* * *}$

$153 \sim 328 \quad 7.93^{* * *}$

Each of the two parental cultivars and each progeny array consisted of six replicates. * and $* * *$ indicate the level of statistical significance at $\mathrm{P}<0.05$ and $\mathrm{P}<0.001$, respectively. ${ }^{\mathrm{ns}}$ indicates no statistical differences for the two parental cultivars for three leaf growth traits. 


\section{Table 2 (on next page)}

Table 2. Analysis of Variance for leaf traits between the two parents and among the 72 genotypes derived from them before exposure to heat stress. 
1

Table 2. Analysis of Variance (ANOVA) for chlorophyll fluorescence $(\mathrm{Fv} / \mathrm{Fm})$ values and hydrogen peroxide $\left(\mathrm{H}_{2} \mathrm{O}_{2}, \mu \mathrm{mol} \mathrm{mgFW}{ }^{-1}\right)$ content among the $72 \mathrm{~F} 1$ progeny arrays at different days of continuous exposure to heat stress.

\begin{tabular}{lcc}
\hline \multicolumn{1}{c}{ Days of exposure } & Range & F value \\
\hline Chlorophyll fluorescence $(\mathrm{Fv} / \mathrm{Fm})$ & \\
0 day & $0.762 \sim 0.807$ & $2.71^{* * *}$ \\
10 day & $0.714 \sim 0.783$ & $2.68^{* * *}$ \\
20 day & $0.603 \sim 0.778$ & $3.01^{* * *}$ \\
30 day & $0.358 \sim 0.776$ & $4.58^{* * *}$ \\
40 day & $0.483 \sim 0.767$ & $25.43^{* * *}$ \\
\hline Hydrogen peroxide $\left(\mathrm{H}_{2} \mathrm{O}_{2}\right)$ & & \\
0 day & $0.15 \sim 0.52$ & $25.76^{* * *}$ \\
40 day & $0.32 \sim 1.74$ & $27.95^{* * *}$ \\
\hline
\end{tabular}

Each of the two parental cultivars and each progeny array consisted of six replicates. $* * *$ indicates the level of statistical significance at $\mathrm{P}<$ 0.001 . 
Figure 1

Temporal changes in chlorophyll florescence (Fv/Fm) values for the two parental cultivars after imposition of heat stress. Each of the two parental cultivars consisted of six replicates.

(O) heat sensitive Norlea (N4) and (O) heat tolerant Kangaroo Valley (K7). * represents the level of statistical significance at $P<0.05$.

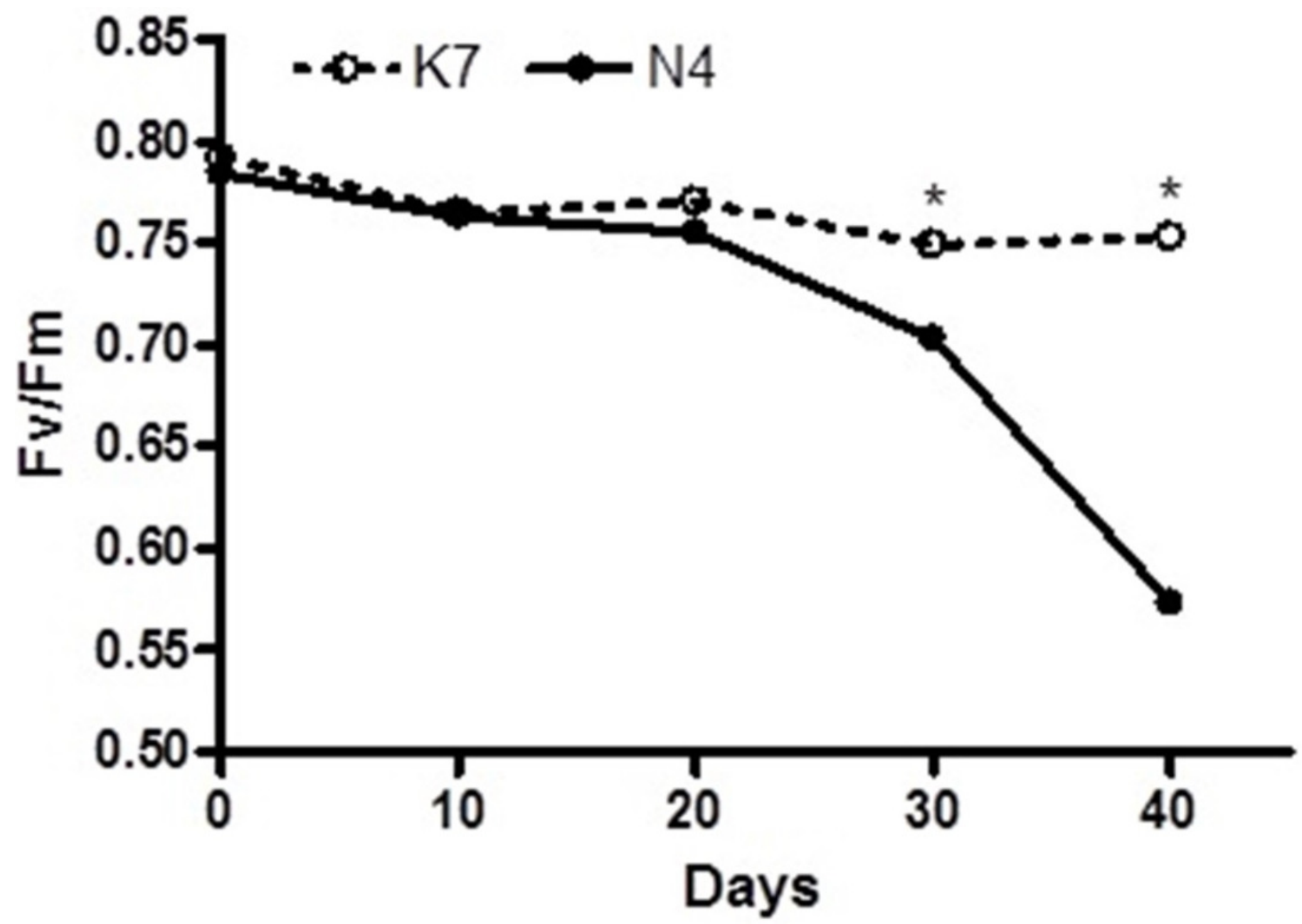


Figure 2

Hydrogen peroxide $\left(\mathrm{H}_{2} \mathrm{O}_{2}\right)$ content before and after the imposition of heat stress in the two parental cultivars. Each of the two parental cultivars consisted of six replicates.

* represents the level of statistical significance at $\mathrm{P}<0.01$.

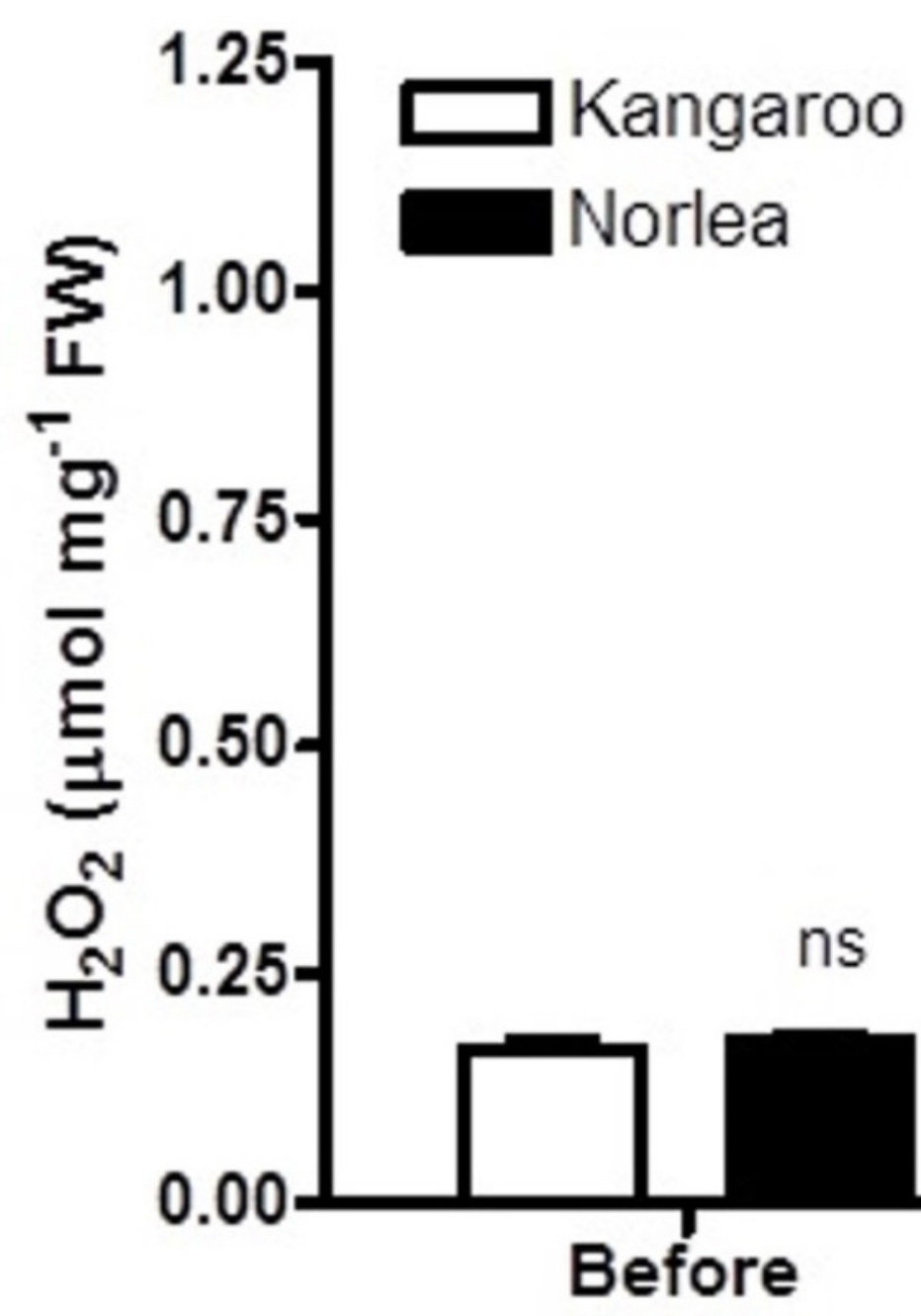

Species

${ }^{*}$ represents the difference at $0.1 \%$ 
Figure 3

Frequency distributions of leaf area (a), specific leaf area (b), leaf water content (c), leaf thickness (d) and leaf density (e) for the $72 \mathrm{~F} 1$ progeny arrays and the two parental cultivars.

(K7) heat tolerant Kangaroo Valley and (N4) heat sensitive Norlea. Each progeny array and each of the two parental cultivars consisted of six replicates. 

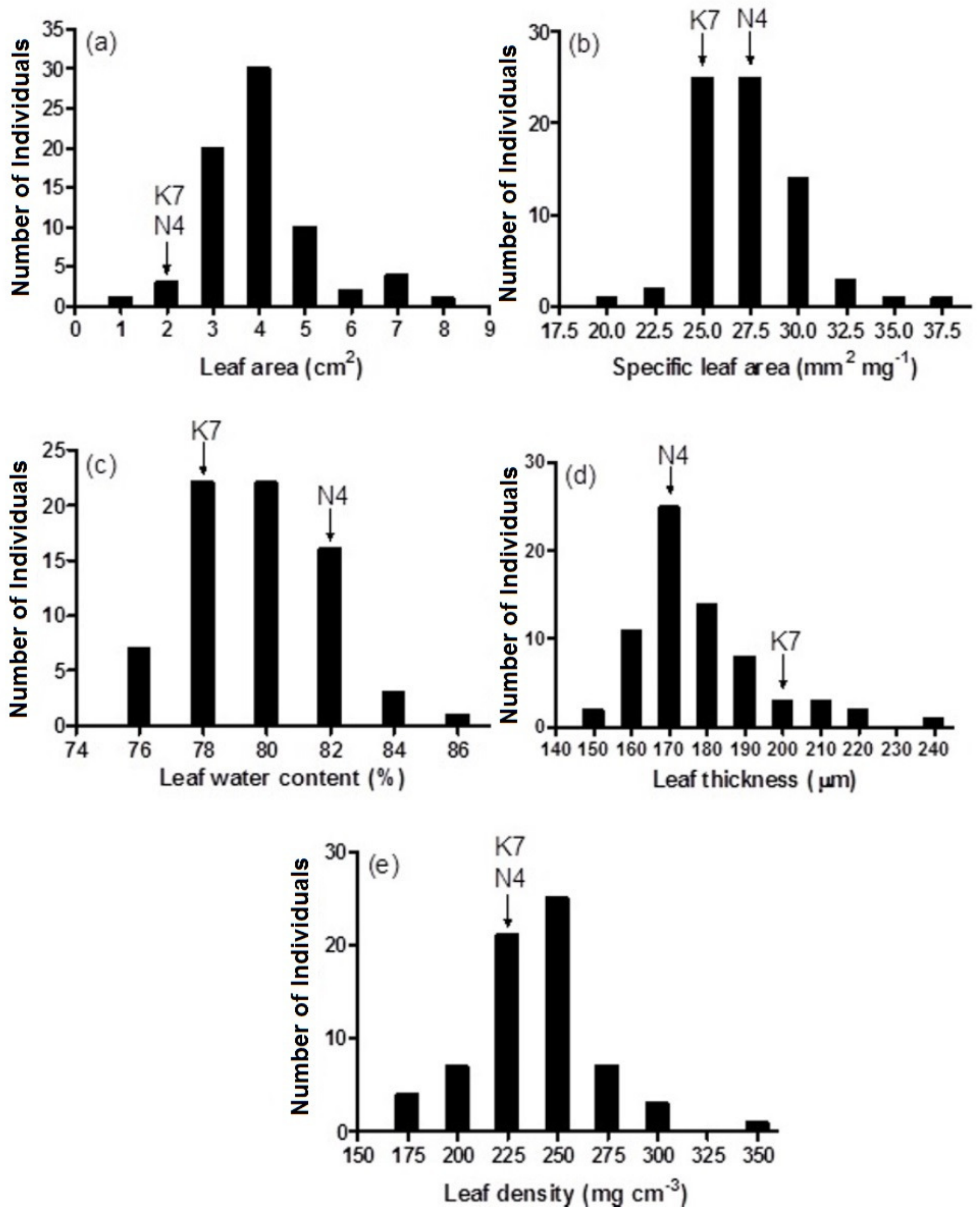
Figure 4

Frequency distribution of (a) chlorophyll fluorescence ( $\mathrm{Fv} / \mathrm{Fm}$ ) and (b) hydrogen peroxide $\left(\mathrm{H}_{2} \mathrm{O}_{2}\right)$ for the $72 \mathrm{~F} 1$ progeny arrays and the two parental cultivars at 40 days of exposure to heat stress.

(K7) heat tolerant Kangaroo Valley and (N4) heat sensitive Norlea, Each progeny array and each of the two parental cultivars consisted of six replicates. 

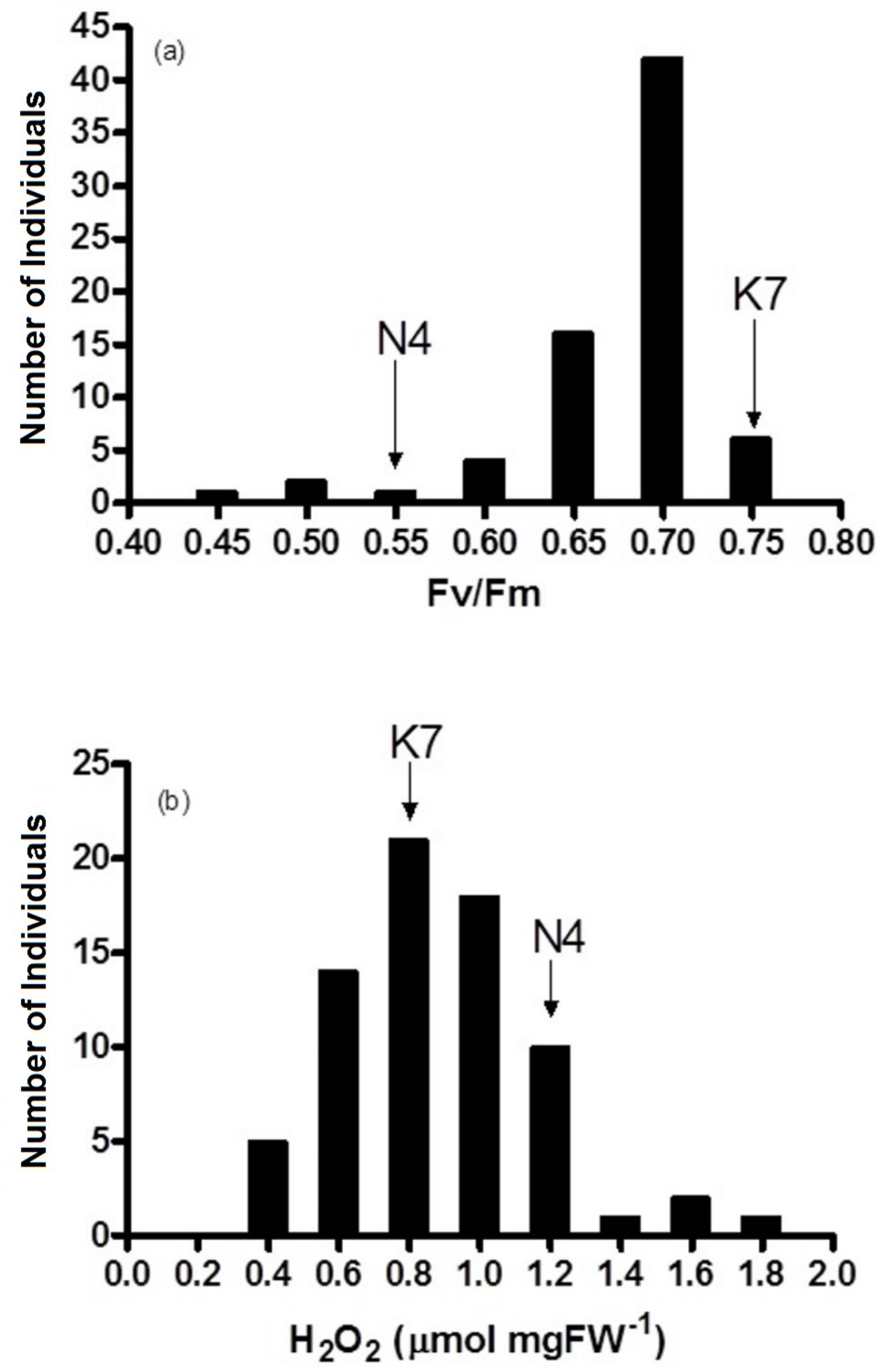
Figure 5

Correlation between chlorophyll fluorescence $(\mathrm{Fv} / \mathrm{Fm})$ and hydrogen peroxide $\left(\mathrm{H}_{2} \mathrm{O}_{2}\right)$ for the $72 \mathrm{~F} 1$ progeny arrays and the two parental cultivars at 40 days of exposure to heat stress.

(K7) heat tolerant Kangaroo Valley and (N4) heat sensitive Norlea. *** indicates the level of statistical significance at $\mathrm{P}<0.001$.

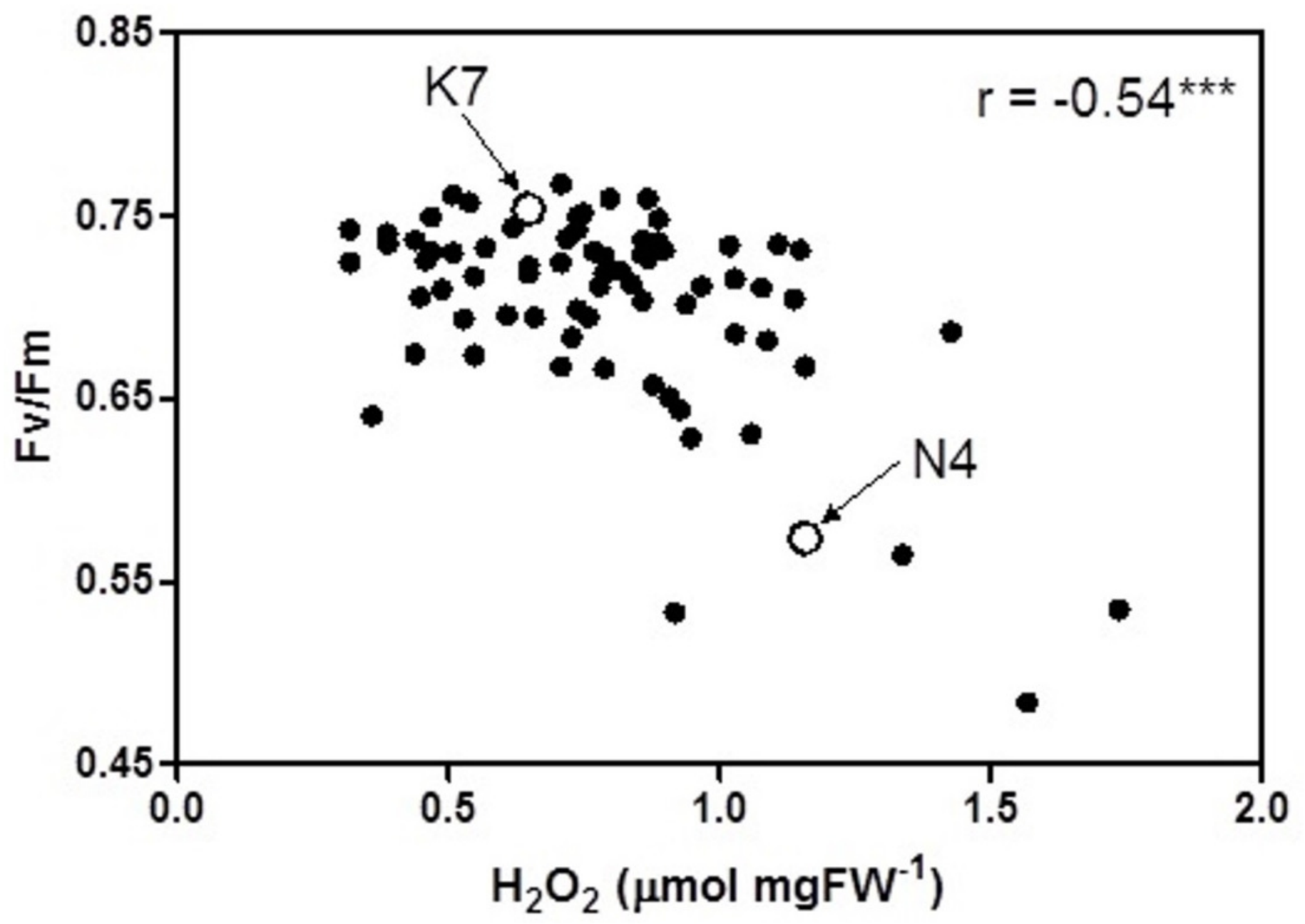

